\title{
ULEARN: Personalized Course Learning Objects Based on Hybrid Recommendation Approach
}

\author{
Shaimaa M. Nafea, Francois Siewe, and Ying He
}

\begin{abstract}
The success of e-learning systems depends on their capability to automatically retrieve and recommend relevant learning content according to the preferences of specific learner profiles. Generally, e-learning systems do not cater for individual learners' needs based on their profile. They also make it very difficult for learners to choose suitable resources for their learning. Matching the teaching strategy with the most appropriate learning object based on learning styles is presented in this paper, with the aim of improving learners' academic levels. This work focuses on the design of a personalized e-learning environment based on a hybrid recommender system, collaborative filtering and item content filtering. It also describes the architecture of the ULEARN system. The ULEARN uses a recommender adaptive teaching strategy by choosing and sequencing learning objects that fit with the learners' learning styles. The proposed system can be used to rearrange learning object priority to match the student's adaptive profile and to adapt teaching strategy, in order to improve the quality of learning.
\end{abstract}

Index Terms-Course content, recommender system, learning object, learner profile, teaching strategy.

\section{INTRODUCTION}

The popularity of e-learning has created huge amounts of educational resources. Hence, locating the suitable learning object that match students learning style as well as teaching strategies has become a big challenge. One way to address this challenge is the use of recommender systems. A recommender system is a tool that helps learner to rate course learning object from a large pool of items. Furthermore, to recommend quality learning materials, it is needed to devise a new approach that is not solely random recommendation of learning object within teaching strategies, but one that takes into account the student's opinion as input for ranking learning object priority. Moreover, it is extremely difficult for a teacher to determine the best learning strategy for each learner and to apply it in a real classroom [1]. One way to address this issue is to use recommender system (RS) techniques to personalize learning process according to the interests and goals of each learner. However, the focus of recent efforts in research has been more on the recommender systems based on the learning content, neglecting the student's input. This work aims to fill that gap through incorporating learners' ratings in the content. Recommender systems can help e-learning by automatically recommending

Manuscript received May 12, 2018; revised June 28, 2018.

Shaimaa M. Nafea is with the School of Business (Management Information System) Arab Academy for Science Technology \& Maritime, Cairo, Egypt (e-mail: P15017421@myemail.dmu.ac.uk).

Francois Siewe and Ying He are with the School of Computer Science and Informatics, De Montfort University, Leicester, UK (e-mail: fsiewe@dmu.ac.uk, ying.he@dmu.ac.uk). the most relevant learning resources to the learners according to their personalized preferences and profile. In this paper, we propose e-learning course content from the combination of two types of recommendation systems collaborative filtering teaching strategies that match personalized learner profile and content filtering learning objects recommendation based on learner rating.

The originalities of proposed model ULEARN are twofold: 1) match student teaching strategy with the appropriate learning objects automatically taking into account the learners rating. 2) Hybrid recommendation is used for selecting from learning object repositories a list of the most appropriate learning objects and adapted to sequence that match adaptive student profile.

The remaining part of this paper is organized as follows. Section II presents the research background on recommender techniques, learning styles, learning objects and mapping teaching strategies to learning objects. Sections III and IV present the proposed model, and introduce the overall system architecture, describing the proposed method, which includes the recommendation framework. The existing work on e-learning RSs is presented in Section V. The conclusion is given in Section VI.

\section{BACKGROUND KNOWLEDGE}

\section{A. Recommender Systems Techniques}

Recommender Systems are software tools for providing a user with suggestions on how to solve a specific problem [2]. In the context of learning objects, these systems seek to make recommendations according to the students' preferences and their learning needs. Five recommendation methods are used in e-learning RSs, namely: Collaborative filtering [3], Content Based [4], Knowledge based [5], the Hybrid approach [6] and Ontology based [7], as shown in Table I.

\section{B. Learning Style}

The learning style of the learner has been identified as an important factor that impacts the learning process. Learning style is the most significant parameter for personalization. Learners differ in their ways of perceiving, processing and receiving information. Based on the means of processing and organizing the information, learners are considered to possess their own style of learning. Fig. 1 shows five dimensions that relate to perception, processing information, information input and understanding information. Currently, Felder Silverman learning style model is considered to be the most stable and appropriate learning style model for adaptive hypermedia learning systems [8]. According to this description, the learning style questionnaire proposes a list of items that are effective in identifying the style of each learner. 
Each dimension has 11 questions and for each question 2 possible answers are available; "a" has the value +1 , while " $b$ " has the value -1 . To assign a dimension to a learner [9], using the questionnaire of Felder-Silverman, it is sufficient to count the number of "a" answers and the number of " $b$ " answers to the 11 questions corresponding to the dimension and to calculate the difference between these two numbers. This measurement is between 11 (all the answers are equal to a) and -11 (all responses are equal to $b$ ). The learner may be close to the " $b$ " end if he has obtained a negative number and vice versa. As an example, when answering a question with a visual preference, the learner's score is incremented by +1 while for verbal preference the score is decreased by 1 .

TABLE I: MAPPING TEACHING STRATEGIES TO LEARNING OBJECTS

\begin{tabular}{|c|c|c|c|c|}
\hline Techniques & Process & Similarity & Algorithms & Drawbacks \\
\hline $\begin{array}{l}\text { Collaborative } \\
\text { filtering }\end{array}$ & $\begin{array}{l}\text { interesting list of } \\
\text { other users in the } \\
\text { community }\end{array}$ & $\begin{array}{l}\text { Cosine or Correlation } \\
\text { based similarity }\end{array}$ & $\begin{array}{l}\text { k Nearest Neighbors } \\
(\mathrm{kNN})\end{array}$ & $\begin{array}{l}\text { spare coverage problem, latency state problem, new } \\
\text { item rating problem, new user problem, cold-start }\end{array}$ \\
\hline $\begin{array}{l}\text { Content } \\
\text { based }\end{array}$ & $\begin{array}{l}\text { contents of web } \\
\text { pages }\end{array}$ & $\begin{array}{l}\text { description of items in } \\
\text { the user profile (a set of } \\
\text { attributes identifying } \\
\text { the items),item-item } \\
\text { relationship }\end{array}$ & $\begin{array}{l}\text { document modeling, } \\
\text { information filtering, } \\
\text { information } \\
\text { extraction }\end{array}$ & $\begin{array}{l}\text { overspecialized problem, dependent on the } \\
\text { availability of content, syntax based, } \\
\text { recommendation (losing semantic meanings) }\end{array}$ \\
\hline $\begin{array}{l}\text { Knowledge } \\
\text { based }\end{array}$ & $\begin{array}{c}\text { Psychographic } \\
\text {,demographic, } \\
\text { personal } \\
\text { attributes of users }\end{array}$ & case-based-reasoning & Decision Rules & subjective and static user profile \\
\hline $\begin{array}{l}\text { Hybrid } \\
\text { filtering }\end{array}$ & $\begin{array}{l}\text { It combines two } \\
\text { or more } \\
\text { recommendation } \\
\text { techniques in } \\
\text { order to improve } \\
\text { the performance }\end{array}$ & $\begin{array}{c}\text { utilized in } \\
\text { collaborative } \\
\text { and content based } \\
\text { similarity }\end{array}$ & $\begin{array}{l}\text { Weighted Method, } \\
\text { Switching Method, } \\
\text { Feature combination, } \\
\text { Cascade ,Feature } \\
\text { Augmentation }\end{array}$ & ------------------------------------------------ \\
\hline $\begin{array}{l}\text { Ontology } \\
\text { based }\end{array}$ & $\begin{array}{l}\text { It contains a set of } \\
\text { concepts namely } \\
\text { entities, attributes } \\
\text { and properties } \\
\text { related to a } \\
\text { domain along } \\
\text { with their } \\
\text { definitions and } \\
\text { relations among } \\
\text { them }\end{array}$ & $\begin{array}{l}\text { Taxonomy similarity } \\
\text { (TS ) } \\
\text { Relation similarity } \\
\text { (RS ) } \\
\text { Attribute similarity } \\
\text { (AS ) }\end{array}$ & $\begin{array}{l}\text { concept diagram or } \\
\text { an ontology } \\
\text { describing a } \\
\text { knowledge base }\end{array}$ & 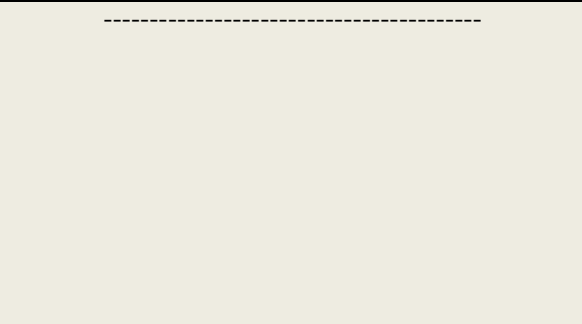 \\
\hline
\end{tabular}

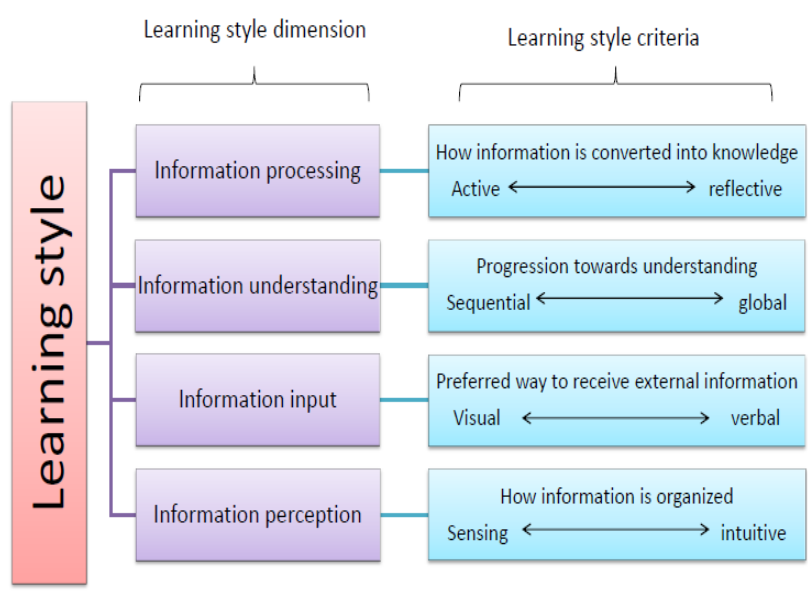

Fig. 1. FSLSM learning style.

\section{Learning Object}

Learning objects are a new way of thinking about learning content design, development and reuse. Instead of providing all of the material for an entire course or lecture, a learning object only seeks to provide material for a single lesson or lesson topic within a larger course. Examples of learning objects include simulations, interactive data sets, exercises, assessments, annotated texts and adaptive learning components. In general, learning objects have the following characteristics: self-contained, reusable, can be aggregated, and tagged with metadata [10]. Learning objects can use many ways to express knowledge, such as text, video and audio etc.

International efforts have been made to develop standards and specifications about learning objects since the late 1990s.

The IEEE Learning Technology Standards Committee, IMS Global Learning Consortium, Inc., and CanCore Initiative [11] are organizations active in this area. IEEE LOM Standard is a multipart standard, which contains a Standard for Learning Objects.

\section{Mapping Teaching Strategies to Learning Objects}

Teaching strategies are the essential element given to the students by the teachers to encourage a more profound understanding of the new information. Teaching strategies must be designed in a way that students are encouraged to observe, analyze and search for new knowledge by themselves. Teaching strategy refers to a composed and systematized activity sequence as well as resources that can be used while teaching. The main objective is to facilitate the students' learning [12]. Table II shows the relationship between the appropriate teaching strategy and material for each learner based on their adaptive profile [13]. For example, for a visual student the content must use visual representations and images. The teacher can also use simulations and games to make it easier for the students to remember the contents. Learning objects are displayed based on the recommended teaching strategies that match the 
learner's profile. Once the teaching strategies are obtained the Dynamic Learning Objects will be recommended, along

with the most appropriate electronic media.

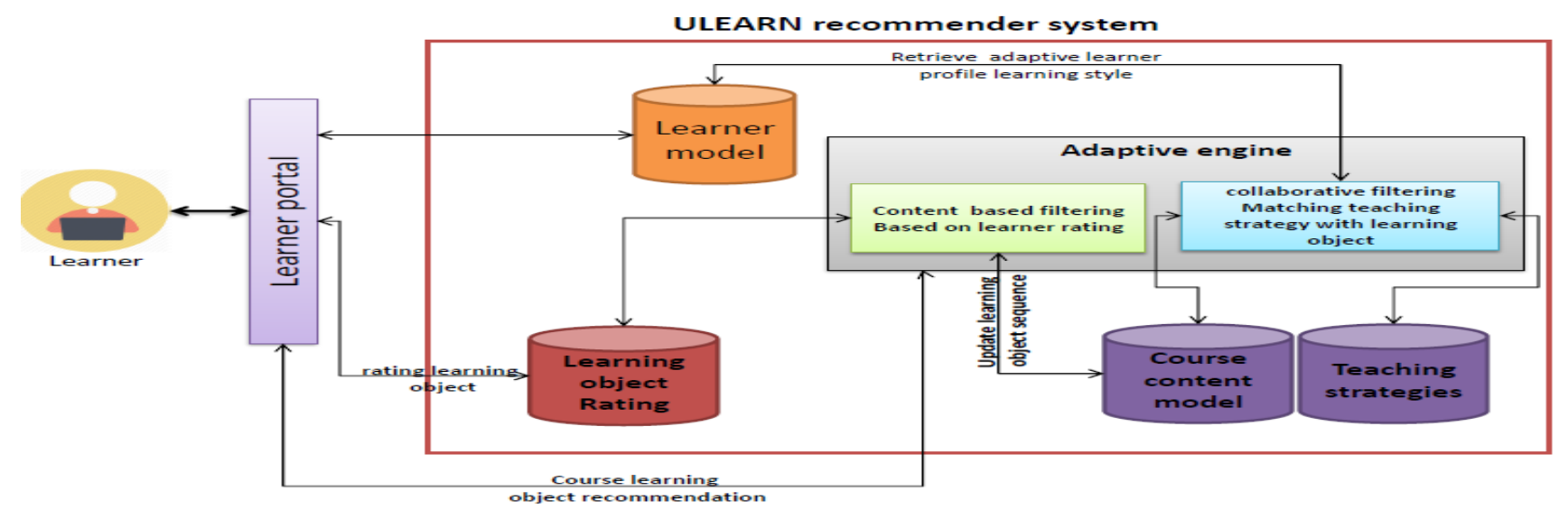

Fig. 2. ULEARN recommender system.

TABLE II: MAPPING TEACHING STRATEGIES TO LEARNING OBJECTS

\begin{tabular}{|l|l|}
\hline Teaching strategies & learning object \\
\hline Games and simulations & $\begin{array}{l}\text { Electronic Presentations, Videos } \\
\text { Animations }\end{array}$ \\
\hline $\begin{array}{l}\text { Learning based on } \\
\text { problem solving }\end{array}$ & Forums \\
\hline Role playing & $\begin{array}{l}\text { Electronic Presentations, Digital } \\
\text { Magazines, } \\
\text { Digital Newspapers }\end{array}$ \\
\hline Presentation & audio conference \\
\hline Discussion panel & Forums,Wikis,E-mail \\
\hline Brainstorming & Chats, blog, Forums \\
\hline Case study & E-books \\
\hline $\begin{array}{l}\text { Question and answer } \\
\text { method }\end{array}$ & $\begin{array}{l}\text { Higher Order Thinking Questions } \\
\text { Simplify the Question MCQ , Essay }\end{array}$ \\
\hline Project design method & Internet research \\
\hline
\end{tabular}

\section{PROPOSED RECOMMENDER MODEL (ULEARN)}

The ULEARN RS will recommend useful and interesting learning resources to learners based on their preferences in the e-learning context. The system was organized using four basic components: learner model, course content model, learning object rating and adaptive engine. These four components interact with the learner to achieve a relevant instructional process. Fig. 2 illustrates the ULEARN course content architecture. The following subsections will briefly explain the framework.

\section{A. Learner Model}

The profile is a generic term that organizes the learner into several categories. This is an individual characteristic that plays an important role in the success of learning. The learner profile describes how the learner learns best. It is practically the representation of the learner's data and it can be gathered in two ways: from the student or by analyzing his/her behavior through a learning management system. First ULEARN initializes a student profile based on the FSLSM questionnaire and then the system starts to update the learner profile based on their behavior. For a learner with (visual, Active, sensing, sequential ) their profile is updated and course content is generated based on their adaptive profile.
For a learner with information input visual, the generated condition is visual etc. Fig. 3 shows the structure of the learner's profile according to the FSLSM model.

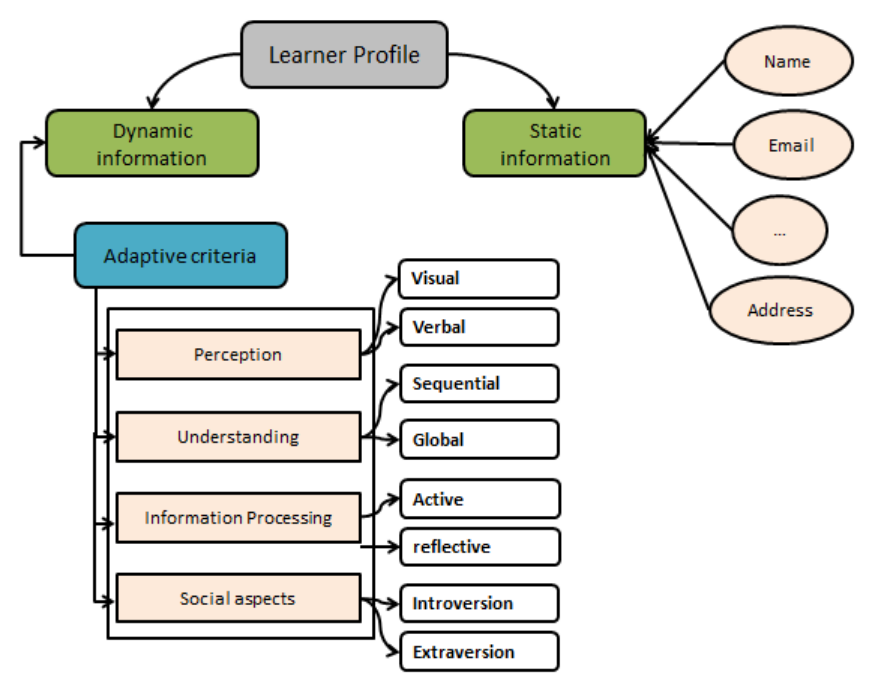

Fig. 3. Learner profile.

\section{B. Course Content Model}

The course content model contains all the knowledge for a particular course. It involves three layers; firstly each course is divided into several topics, and each topic is presented by a set of lessons. Finally each lesson is associated with different learning objects as shown in Fig. 4. Topic is presented by a set of Lessons. Finally each Lesson is associated with different learning objects as shown in Fig. 4.

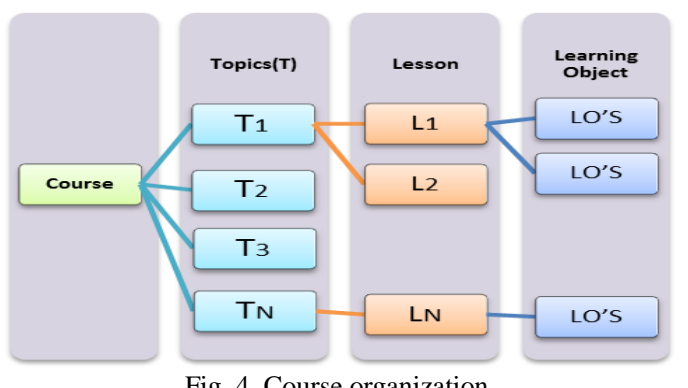

Fig. 4. Course organization.

\section{Learning Object Rating}

The learning object recommendation sequence is based on 
the learners' ratings. The learning object sequence takes into consideration the evaluation of the content i.e. the number of stars given for this content, learner reputation and the number of likes and dislikes.

$$
\text { Rating } \mathrm{LO}=\sum(\mathrm{L})+\sum(\mathrm{C})
$$

Equation 1 represents, the total number of evaluations of a learner and $\Sigma(\mathrm{L})$ represents the total number of evaluations of the contents of this learner. After weighting the learning object as shown in Table III, we obtained a preference model for each learner defined as a Learner-Learning Object Rating (RatingLO) matrix where $\mathrm{L}$ denotes the number of learners $\mathrm{L}$ $=\left\{\mathrm{L}_{1}, \mathrm{~L}_{2}, \ldots . \mathrm{L}_{\mathrm{n}}\right\}$, and $\mathrm{VC}$ columns denote the number of learning objects $C=\left\{C_{1}, C_{2}, \ldots, C_{m}\right\}$. After calculating the learning object rating, the adaptive engine starts to take a weighted average of all the ratings of those learning objects. RatingLO: refers to the learners' vote for learning object satisfaction level. This evaluation takes the form of a scale from zero stars to five stars as follows: Null $=0$, Poor $=1$, Medium $=2$, Good =3, Very good $=4$, Excellent $=5$.

TABLE III: SAMPLE FROM LEARNER RATING

\begin{tabular}{|l|l|l|l|}
\hline Learners & $\mathbf{L O}_{\mathbf{1}}$ & $\mathbf{L O}_{\mathbf{2}}$ & $\mathbf{L O}_{\mathbf{3}}$ \\
\hline Fatma & 2 & 4 & Unrated \\
\hline Tom & 1 & 3 & 5 \\
\hline Clara & 3 & 5 & 2 \\
\hline
\end{tabular}

\section{Cleaning and Preprocessing}

Data preprocessing is a recommender task for reducing the scale of the dataset in a good way to enhance the quality of the recommend learning objects. Imagine that we have 3 objects $-1,2$ and 3 . Suppose that we have simple one-dimensional ratings by users Fatma, Tom, and Clara as follows. We see that Fatma did not rate Object 3. One approach is to calculate the average Object 3 rating based on learners Tom, and Clara; third learner rating on Object 3.

We adopted this equation for the e-learning content so that we can rate all of the learning objects by characterizing the score function $\mathrm{S}$

$$
\mathrm{S}(0)=1 / 2(\mathrm{E}(0)+\mathrm{I}(0))
$$

where $E(0)$ is the explicit score given by the learner for each learning object 0 and $\mathrm{I}$ is the implicit score that is defined by how much time is spent on each learning object.

$$
I(\theta)=\frac{\text { time spent }}{\text { total time }}
$$

\section{E. Adaptive Engine}

The adaptive engine is the core inside the learning adaptation process; it is the core of our proposed system. This is the decision body, allowing the association to be made between the most suitable teaching techniques and learning objects, based totally on the learner's adaptive profile. Matching a teaching strategy with a learning object module helps to decide whether or not a given teaching approach is suitable for a particular learning style. This module uses collaborative filtering to categorize a teaching strategy as "suitable" or "not suitable" for the learner. Learning objects are displayed based on the recommended teaching strategies that match the learner's profile. Once the teaching strategies are obtained the Dynamic Learning Objects will be recommended, along with the most appropriate electronic media.

\section{ULEARN COURSE RECOMMENDATION FLOWCHART}

Fig. 5 shows the course adaptation sequence in the ULEARN RS.A new learner signs up by completing the FSLSM learning style questionnaire and this initializes their adaptive learner profile. After that the ULEARN algorithm selects the most suitable teaching strategies that match the learners' learning styles. Then the ULEARN similarity algorithm will be applied to measure the similarity between the learner profile and course learning objects.

\section{ULEARN IMPLEMENTATION}

The ULEARN RS has been implemented with Java and an SQL server. The main purpose of the system is to recommend useful and personalized teaching strategies and learning objects, based on learner preferences in the e-learning context. Therefore, the proposed system includes separate user interfaces based on the user's role, e.g. learners and instructors. The instructor's interface helps to manage data about a learner and course material.

Three main roles exist in the ULEARN system:

1) Learner's portal: The learner's portal sequence of pages changes depending on whether the learner has just entered the system or is continuing his/her course. Once the learner is registered, they answer the learning style assessment questionnaire in order to initialize the adaptive learner profile, as shown in Fig. 6 and 7.

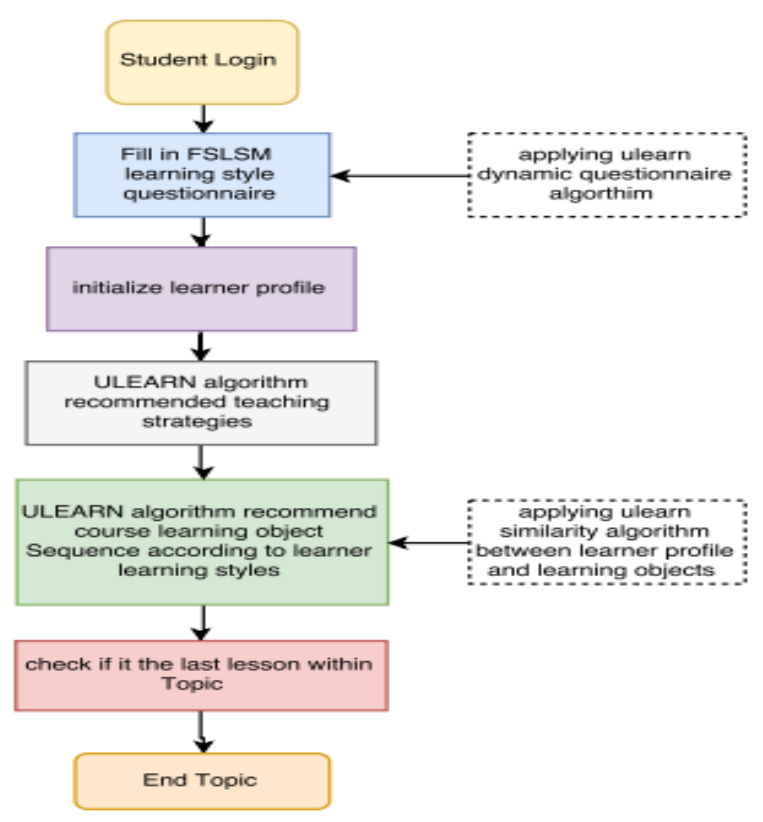

Fig. 5. Proposed student profile flowchart.

2) Instructor portal: this allows the instructor to add courses, lessons and learning objects in different learning styles as well as to add assignments

3) Administrator portal: this allows the administrator to 
assign learners and instructors to specific courses in addition to managing the system's database.

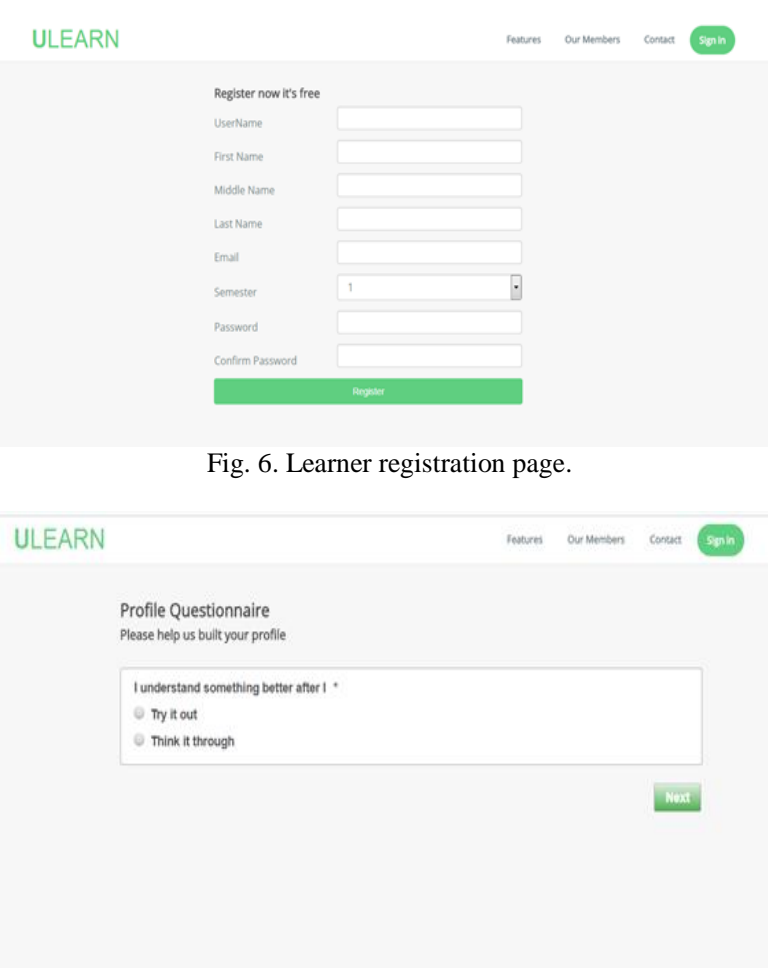

Fig. 7. FSLSM questionnaire.

\section{USE-CASES APPLICATION SCENARIO}

The following user case study presents how teaching strategies and learning objects will be recommended based on the learner adaptive profile. For example, Tom's adaptive profile learning style is visual, active, sensing and sequential so the recommended teaching strategies are problem solving then presentation and finally project design. According to the problem-solving teaching strategy, learning objects will be recommended based on the learners' rating. The system will start by recommending forum discussions, then video conferencing and then simulation, as shown in Fig. 8.

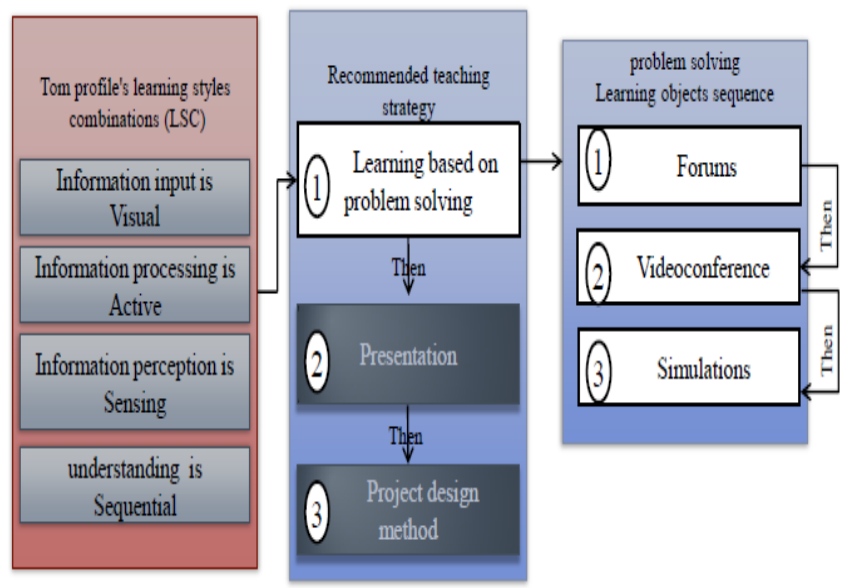

Fig. 8. Teaching strategies and learning objects recommendation scenario.

\section{RELATED WORK}

In this section, we summarize and compare e-learning recommendation approaches as shown in Table IV:
TABLE IV: THE COMPARISON OF E-LEARNING RECOMMENDER APPROACHES

\begin{tabular}{|l|l|l|l|}
\hline Author & $\begin{array}{l}\text { Recommend } \\
\text { Approach }\end{array}$ & $\begin{array}{l}\text { Learner's } \\
\text { Context }\end{array}$ & $\begin{array}{l}\text { Items } \\
\text { Recommended }\end{array}$ \\
\hline$[14]$ & $\begin{array}{l}\text { Content based } \\
\text { recommendation }\end{array}$ & $\begin{array}{l}\text { Good learners' } \\
\text { average rating on } \\
\text { the viewing } \\
\text { learning object. }\end{array}$ & $\begin{array}{l}\text { Recommend } \\
\text { similar learning } \\
\text { object to the } \\
\text { Viewing item. }\end{array}$ \\
\hline$[15]$ & $\begin{array}{l}\text { profile-based } \\
\text { filtering } \\
\text { recommendation }\end{array}$ & $\begin{array}{l}\text { giving learners } \\
\text { the possibility to } \\
\text { add new } \\
\text { materials and to } \\
\text { rate them }\end{array}$ & $\begin{array}{l}\text { adapt suitable } \\
\text { sequencing } \\
\text { learning content to } \\
\text { learners }\end{array}$ \\
\hline$[16]$ & $\begin{array}{l}\text { user-item- based } \\
\text { recommendation }\end{array}$ & $\begin{array}{l}\text { learners' average } \\
\text { rating and } \\
\text { analysis } \\
\text { students' } \\
\text { behavior }\end{array}$ & $\begin{array}{l}\text { Recommend } \\
\text { learning material } \\
\text { based on } \\
\text { difficultly level } \\
\text { since the } \\
\text { knowledge level of } \\
\text { a user } \\
\text { continuously }\end{array}$ \\
\hline
\end{tabular}

This overview demonstrates that the major purpose of e-learning RSs is to deliver personalized course content in order to meet learners' needs such as their learning style, preferences and knowledge levels etc. In spite of the fact that $\mathrm{CF}$ [17] is one of the most popular recommendation algorithms [18], the hybrid approach has become popular in recent publications because it improves e-learning recommendation accuracy [19].

\section{CONCLUSION}

In this paper, we presented the ULEARN, which is an intelligent personalized course content RS for different learning styles and teaching strategies. It recommends a method by mapping distinctive student styles with appropriate learning objects and teaching strategies. ULEARN supports the recommendation of learning objects that are the best fit for every particular student, taking into consideration the wide variety of student profiles. The prototype ULEARN is currently undergoing testing with several sets of learning materials. In the future, we intend to experiment with ULEARN on a large number of learners over a long period of time to test the viability of our proposed approach.

\section{REFERENCES}

[1] E. Abelwahed et al., "Anadaptive teaching strategy model in e-learning using learners preference: learnFit framework," Int. J. Web Sci., vol. 1, no. 3, pp. 257-274, 2012.

[2] C. Figueroa, I. Vagliano, O. R. Rocha, M. Torchiano, C. F. Zucker, J. C. Corrales, and M. Morisio, "Allied: A framework for executing linked data-based recommendation algorithms," International Journal on Semantic Web and Information Systems (IJSWIS), vol. 13, no. 4, pp. 134-154, 2017.

[3] C. Kadie et al., "Empirical analysis of predictive algorithms for collaborative filtering," in Proc. the Fourteenth Conference on Uncertainty in Artificial Intelligence, Morgan Kaufmann Publishers Inc., 1998.

[4] W. M. Smeulders Arnold et al., "Content-based image retrieval at the end of the early years," IEEE Transactions on Pattern Analysis and Machine Intelligence, vol. 22, no. 12, 2000, pp. 1349-1380.

[5] S. Aravind et al., "Gene set enrichment analysis: A knowledge-based approach for interpreting genome-wide expression profiles," in Proc. the National Academy of Sciences, 2005, pp. 15545-15550.

[6] W. Robert, W. Umbrath, and A. Said, "A hybrid approach to item recommendation in folksonomies," in Proc. the WSDM'09 Workshop 
on Exploiting Semantic Annotations in Information Retrieval, ACM, 2009.

[7] I. Wouter et al., "Ontology-based news recommendation," in Proc. the 2010 EDBT/ICDT Workshops, ACM, 2010.

[8] Silva, D. Hugo, and F. A. Dora, "An automatic approach for customization of teaching process based on learning styles in adaptive and intelligent learning systems," Brazilian Journal of Computers in Education, vol. 22, no. 02, 2014, p. 1.

[9] B. Ahmed et al., "Generation of pedagogical content based on the learning style of learners in a dynamic adaptive hypermedia environment," 2014.

[10] D. Declan, V. Wade, and O. Conlan. "Towards a standards-based approach to e-learning personalization using reusable learning objects," E-Learn: World Conference on ELearning in Corporate, Government, Healthcare, and Higher Education. Association for the Advancement of Computing in Education (AACE), 2002.

[11] B. Phil and L. M. Campbell, "Metadata for learning materials: An overview of existing standards and current developments," Technology, Instruction, Cognition \& Learning, vol. 7, 2010.

[12] C. R. Jack and T. S. Rodgers, Approaches and Methods in Language Teaching, Cambridge University Press, 2014

[13] N. Pukkhem and V. Vatanawood, "Personnalised learning object based on multi-agent model and learner's learning styles," Journal of Science and Teachnology, vol. 5, no. 3, pp. 292-311, 2011.

[14] K. Ghauth and A. Abdullah, "Building an e-learning recommender system using vector space model and good learners average rating," presented at Ninth IEEE International Conference on Advanced Learning Technologies, IEEE, 2009.
[15] R. F. C. Quaresma et al., "Hybrid recommender strategy in learning: An experimental investigation," Socialines Technologijos, vol. 3, no. 1, 2013.

[16] K. Christopher, "Smart learning: Time-dependent context-aware learning object recommendations," presented at FLAIRS Conference, 2016.

[17] F. Abel, I. I. Bittencourt, E. Costa, N. Henze, D. Krause, and J. Vassileva, "Recommendations in online discussion forums for e-learning systems," IEEE Trans. Learn. Technol., vol. 3, no. 2, pp. 165-176, Apr.-Jun. 2010.

[18] M. H. Hsu, "A personalized English learning recommender system for ESL students,” Expert Syst. Appl., vol. 34, no. 1, pp. 683-688, 2008.

[19] H. Sobhanam and A. K. Mariappan, "A hybrid approach to solve cold start problem in recommender systems using association rules and clustering technique," Int. J. Comput. Appl., vol. 74, no. 4, pp. 17-23, 2013.

Shaimaa M. Nafea is a $\mathrm{PhD}$ student. She received her master's degree in information system from Arab academy for science and technology and maritime transport. Her main research interests are in adaptation and personalization of e-learning environment, ontology, recommender systems and collaborative filtering, machine learning. 